\title{
Columbia inquiry homes in on faulty foam
}

\section{Tony Reichhardt, Washington}

The official investigation into the loss of the space shuttle Columbia on 1 February is fast closing in on the accident scenario that seemed most likely in the first place. A piece of foam insulation, investigators believe, fell from the shuttle's external fuel tank shortly after launch, damaging the shuttle's left wing and causing it to overheat on re-entry.

The Columbia Accident Investigation Board, chaired by retired US Navy admiral Hal Gehman, compared notes with NASA's own investigators in a closed meeting on 24 April. The most likely scenario is that the foam damaged a T-shaped seal between two curved sections of insulation on the wing's leading edge. The seal then came loose while the craft was in orbit, creating a gap that allowed superheated gases to enter the wing when Columbia re-entered the atmosphere.

This scenario fits with evidence from the examination of recovered debris, data returned from the shuttle before it broke up, radar signals from material that floated away from Columbia in orbit, and data from a sensor package recovered in March, according to members of Gehman's board.

But there still are key gaps in the analysis. Whether falling foam could have caused the damage to the T-seal, even at high velocities, will be determined in part by impact tests to be carried out later this month. NASA and the Gehman board have been investigating areas on the fuel tanks where foam can come loose, and the board may recommend that NASA revises its approach to applying the foam before shuttle flights can resume. Also under scrutiny are the reinforced carbon-carbon panels and T-seals, which may have weakened with age.

Finally, the board will consider NASA's decision-making processes, and whether shuttle managers should have recognized that past problems with falling foam were more serious than they had thought.

Meanwhile, a two-man crew arrived on the International Space Station on Monday for a six-month stay, on board a Russian Soyuz vehicle. Their supplies will be delivered by Russian Progress capsules.

Little research will be done on the station until the shuttle resumes deliveries of laboratory equipment, however. The next flight was to have brought up a second facility for research on human physiology, equipment for Earth observation, and a freezer for biological specimens. Subsequent flights would have boosted electrical power on the station by adding solar arrays.

But space-station crews can do research in the area of human adaptation to space, says Milburn Jessup, a professor of oncology at the Georgetown University Medical Center in Washington DC, and chair of the space-station scientific users' committee.

NASA is expected to take around a year to get the shuttle flying again. Michael Kostelnik, deputy head of the agency's shuttle and

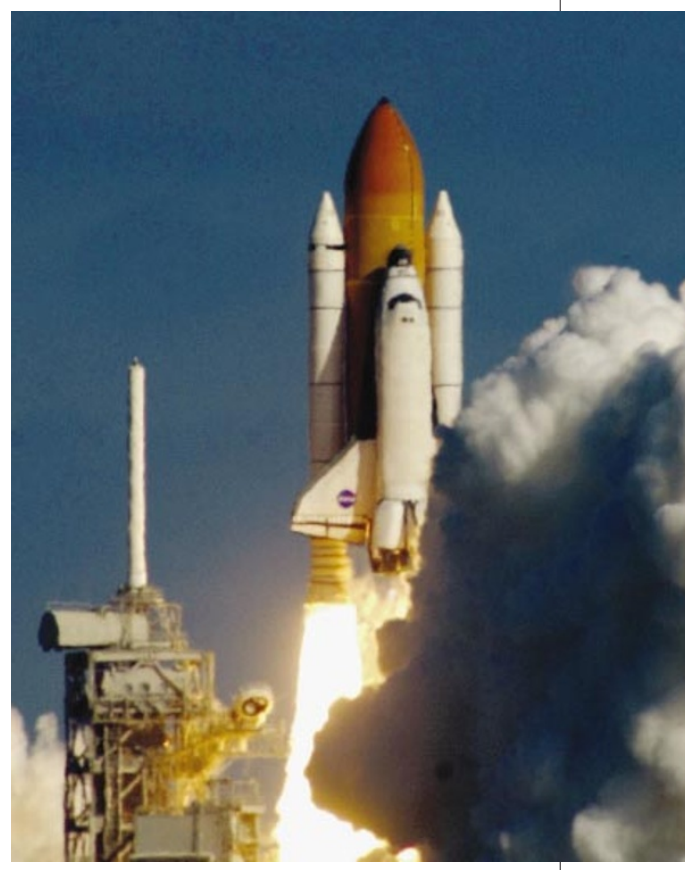

Crumbling foam from the nose of Columbia's launcher (orange) may have damaged the craft.

space-station programmes, says a resumption of shuttle flights between next January and March is "hopefully possible". But scientists who are familiar with space-station planning say that flights are more likely to resume in summer 2004.

\section{Stealth ship sets sail for a quiet life fishing for data}

\section{John Moore, Cork}

The world's quietest research vessel set sail last month on its first scientific mission. By using low-noise electric engines and mounting equipment on rubber, Ireland's ๙ 32-million (US\$35-million) Celtic Explorer should be able to approach fish more closely, improving the accuracy of fishery surveys.

Noise from ships is recognized as a major source of bias in such surveys, according to a

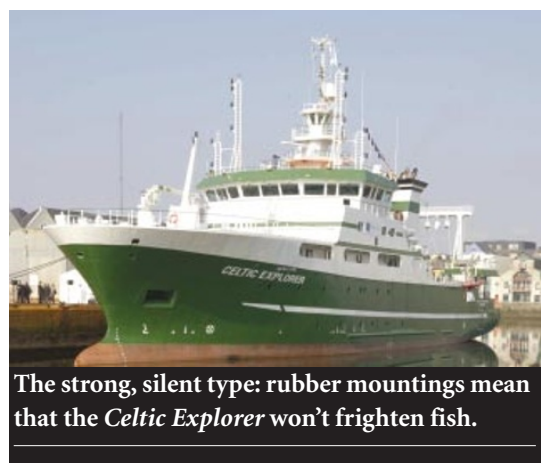

1995 report by the International Council for the Exploration of the Sea (ICES). Low-frequency sounds from vessels cause fish to stay 100-200 metres from some ships, and up to 400 metres from noisier ones.

Only two other vessels - the Scotia and the Corystes, both based in Britain - meet targets cited in the ICES report for reducing the sound from ships, and the Celtic Explorer outperforms them both. "Its performance is better than any fisheries research vessel measured to date," says the report's author, Ron Mitson of Acoustec in Lowestoft, UK, a company that advises ICES on underwater noise levels.

Most noise from ships is caused by pumps, engines and the propeller, or by protrusions on the hull that generate bubbles in the water. On the Celtic Explorer, all of the equipment is rubber-mounted onto the hull. The propeller mounting also reduces noise, by fixing the propeller in a set position, rather than allowing its angle to be adjusted as on some other vessels.
The ship's project manager, Michael Gillooly of the Marine Institute in Galway, Ireland, adds that the resulting low noise levels reduce interference in the sonar systems that are used to survey fish.

Celtic Explorer, which can accommodate 19 scientists, will conduct a seabed survey around Ireland until October, with the aim of producing maps for telecommunications applications, management of underwater hazards, and the protection of areas of scientific interest. In November, it will carry out a survey of fish such as cod and plaice that live on or near the bottom of the ocean.

Other countries outside Europe are also developing vessels that can fulfil the ICES guidelines. "We are currently in the middle of constructing the first of four new vessels designed and contracted to meet the ICES noise standards," says John Hotaling of the US National Marine Fisheries Service in Silver Spring, Maryland. "The first ship, Oscar Dyson, is expected to be launched in September and be in service by late 2004." 